\title{
The Salary Design of Private Higher Education Institution*
}

\author{
Zhong Tingyong ${ }^{1,2}$, An Ye ${ }^{1}$, Li Jiangna ${ }^{2}$ \\ ${ }^{1}$ Guanghua College of Changchun University, Changchun 130117, China \\ ${ }^{2}$ Bussness School of Northeast Normal University, Changchun 130117, China
}

\begin{abstract}
The encouragement and retention is very important for the sustainable development of Chinese private higher education institutions and the designing a suitable salary system can achieve this goal. In this paper, we summarize the problems in these institutions and then propose a design of salary system for them for the purpose that it can promote the institutions.

Index Terms - Salary system, salary design, private higher education institution
\end{abstract}

\section{Introduction}

The talent competition in private higher education institutions decides the productivity of institutions (Katz, 1973), in which the compensation system is the key point in attracting, reserving and encouraging the teachers. However, most private higher education institutions in China construct their salary system imitating the public universities because the private higher education institutions emerged after 1980 which the first private university is Jiuyishan College. There are many differences in these two type university which make the private universities get into trouble. First of all, the difference in the nature of the university between private one and public one decides the labor flow under the condition that excellent teachers would go to the public universities for they can afford the stable compensation which makes the private universities have difficulty in recruiting excellent teachers who can make bigger contribution in teaching and research. Secondly, most private universities make their salary systems without considering their strategy and actual situation which resulting in the fuzziness of motivation. Thirdly, the simplification of the university salary and the lack of adjustment mechanism lead to the lack of motivation. Fourthly, the payment idea is unclear for the university salary unconnected with ability and performance. Lastly, insufficiency survey in market salary makes the lack of external competitiveness in attracting teachers. For this purpose, designing a salary system for China's private intuitions considering their strategy is important for the sustainable development. The key points of design salary must keep internal fairness and external competitiveness. In this paper we plan to interpret how to make a private university salary system in detail and the followed chart summarizes the process.

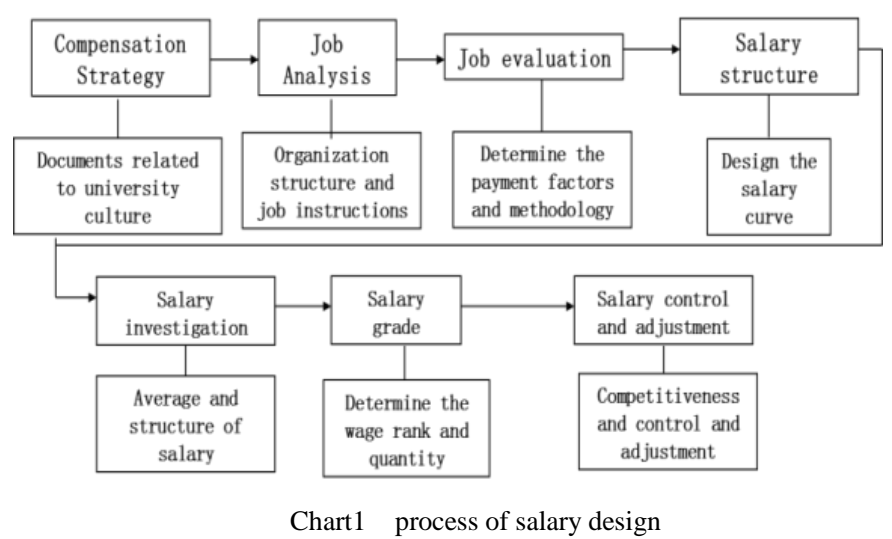

\section{Compensation Strategy}

The right compensation strategy with the appropriate compensation structure will help universities attract and retain critical employees. As the first step, making the compensation strategy according to the university strategy is the fundament of the following steps, which is comprised of acquaintance of humanity, valuation of staff and compensation policy. Therefore, making a good salary system should follow these principles:

(1) should consider how to reflect the strategy, in other words, how to realize the short, medium-term and long-term object.

(2) motivation which reflects the difference in efforts by person and improving the ability to adapt the development of universities.

(3) responsibility which determines the compensation according to contribution not to the administrative level.

\section{Job analysis and job evaluation}

\section{A. Job analysis}

The task of job analysis is to design the organization structure of the institutions, analyze position requirements and staff which is the fundament of determining the compensation. To do so, the department of human resource of an institution should make a plan to collect everything related to the job, classify the job into different position (for example, the teacher job can be divided into an assistant, a lecturer, an associate professor and a professor), summarize the requirement of every position and at last compile the job specifications, which can be used to define the relationship of function and position.

\footnotetext{
* Supported by Jilin Education Science Planning Project (ZC11172)
} 


\section{B. Job evaluation}

Job evaluation is to make work level so as to determine the criterion of salary for one worker which is used to make sure the fairness of the salary. The purpose of the job evaluation is to compare the importance of each position to gain the job grade sequence and offer a standard for the salary investigation to eliminate the difference in job of institutions or the difference in the requirement of work and its name. A private university implement the job evaluation can choose one of the famous two methodologies named HAY model and CRG model which evaluate a job quantitatively with three factors and many other sub factors.

The salary level comes from the reasonable job evaluation system by evaluate the different factors related the job not from the connection with the position, which is the most important factor of a university's salary system. The organization structure of a private institution and job specifications are the result of job analysis and job evaluation. The accuracy of the above work is necessary for the internal fairness by using specific amount of money to reflect the relative value of a job.

\section{Salary Survey Analysis}

Salary survey analysis is the process of analyzing compensation data gathered from other employers in a survey of the relevant labor market. Gathering external pay data (e.g., base pay, bonuses, stock options and benefits) is essential to keep the private institution's compensation externally competitive within its industry. Employee attraction and retention can be improved by maintaining externally aligned pay structures. A consulting company is thought to be better than the human resource department of an institution to implement this work both of who are faced two questions:(1)investigate what and (2) how to investigate. Three principles should be insisted for that firstly, the average salary of teachers in nationwide and local labor markets should be collected and the salary information of the major competitors in the same area may be more useful. Secondly, the structure and items of the compensation of all other private and public universities is the important information for forming the salary system. The last is the adjustment mechanism of salary.

\section{Salary Grade Design}

A salary grade is a step within a compensation system that defines the amount of pay an employee will receive. The salary grade is generally defined by the level of the responsibilities performed within the job description of the position and the length of time the employee has performed the job.

Salary grades are used by many famous universities to help managers manage the compensation of new employees and establish appropriate pay increases for existing employees while maintaining equity among the jobs in the university. Salary grades provide a structure for fairly compensating employees and managing the payroll. Occasionally, the horizontal axis is related to the performance of the employee as well as the length of the employee's service. The vertical steps in a pay grade chart refer to the level of the responsibilities defined by the job's requirements (an example in table 1)

Table1 Salary table 2010-GS

\begin{tabular}{|c|c|c|c|c|c|c|c|c|c|c|c|}
\hline Grade & Step 1 & Step 2 & Step 3 & Step 4 & Step 5 & Step 6 & Step 7 & Step 8 & Step 9 & Step 10 & GRADE \\
\hline 1 & 17803 & 18398 & 18990 & 19579 & 20171 & 20519 & 21104 & 21694 & 21717 & 22269 & VARIES \\
\hline 2 & 20017 & 20493 & 21155 & 21717 & 21961 & 22607 & 23253 & 23899 & 24545 & 25191 & VARIES \\
\hline 3 & 21840 & 22568 & 23296 & 24024 & 24752 & 25480 & 26208 & 26936 & 27664 & 28392 & 728 \\
\hline 4 & 24518 & 25335 & 26152 & 26969 & 27786 & 28603 & 29420 & 30237 & 31054 & 31871 & 817 \\
\hline 5 & 27431 & 28345 & 29259 & 30173 & 31087 & 32001 & 32915 & 33829 & 34743 & 35657 & 914 \\
\hline 6 & 30577 & 31596 & 32615 & 33634 & 34653 & 35672 & 36691 & 37710 & 38729 & 39748 & 1019 \\
\hline 7 & 33979 & 35112 & 36245 & 37378 & 38511 & 39644 & 40777 & 41910 & 43043 & 44176 & 1133 \\
\hline 8 & 37631 & 38885 & 40139 & 41393 & 42647 & 43901 & 45155 & 46409 & 47663 & 48917 & 1254 \\
\hline 9 & 41563 & 42948 & 44333 & 45718 & 47103 & 48488 & 49873 & 51258 & 52643 & 54028 & 1385 \\
\hline 10 & 45771 & 47297 & 48823 & 50349 & 51875 & 53401 & 54927 & 56453 & 57979 & 59505 & 1526 \\
\hline
\end{tabular}

note: come from $O P M$

An employee who is new to a job in a particular pay grade range starts at pay step one of the pay grade. If he or she continues to work in the same role, the pay grade allows upward movement in salary, usually one pay step per year of service within the pay grade assigned to that job. Compensation systems involving pay grades are often used within public sector employment such as the Federal government, the military, and universities.

Pay steps within each pay grade differ between organizations and may involve as many as $10-15$ or more pay steps before an employee reaches the top rate of pay for their pay grade. A pay raise, once an employee reaches the top of their pay grade is dependent on cost of living allowances or increases. An employee may also obtain a promotion or move 
to a different job with more responsibilities to start moving up the pay steps of the next pay grade level. Overlaps in the amount of salary available at each pay step of the pay grade are common to pay grades. For example, a beginning worker's job at pay grade 1 might involve $10-15$ pay steps from $\$ 18,000$ to $\$ 24,000$. Pay grade 2 assigns rates from $\$ 22,000$ to $\$ 27,000$ and so forth.

As discussed above most job evaluation systems generate a specific point total for each job. Hence, it is possible to build a pay range for the specific point rather than using grades. For example, in a grade based system a 140 point and 142 point job would likely be in the same grade with the same salary midpoint. However it is possible to pay for points with a formula like:

\section{A. Comprehensive value point}

$$
\mathrm{CWP}=\mathrm{TSA} / \Sigma(J V P)
$$

Where the CVP is the comprehensive value point, TSA is the total salary amount which is determined by the university's compensation committee according to the budget, strategy and the average salary of this educational industry and the JVP is the position value point which will multiply an adjustment factor if the university wants to reflect the difference in the value of some important jobs.

\section{B. Total Salary Amount}

$$
\mathrm{TSA}=\mathrm{CVP}: \Sigma(J V P)
$$

\section{The Salary Grade}

The position is divided in to several grades according to the JVP by using different methods named point extension method, geometric extension method and reserved point extension method. Whatever methods you choose, three steps should be included. The first step is to determine how many salary grades to be divided and classify the positions. And then determine the salary grade line and last determine the level of a position according to the position points and the grade line.

\section{$D$. Introducing the Broadbanding}

In a broadband pay structure, the numbers of salary grades are consolidated into fewer, but broader, pay ranges. In broadbanding, the spread of the pay ranges is wider and there is less overlap with other pay ranges.

Broadbanding works better for some organizations than others. Hierarchical and/or risk averse companies with a preference for well-defined policies and procedures would be better served by a traditional multi-grade structure. Flat organizations that are flexible, have a higher tolerance for ambiguity, and encourage lateral or cross functional movement would be good candidates for broadbanding.

For a suitable private university in the right cultural setting, broadbanding can do the following:
- Reward performance more efficiently - as the pay ranges are wide, the company has the flexibility to reward a star performer, even when they are not getting promoted.

- Take the emphasis off of job evaluation - because the number of levels have been reduced, job evaluation can be streamlined as there are not as many distinct grades that need to be considered when slotting a job into the structure.

- Manage a flexible workforce - for companies that have staffing needs that change frequently or are difficult to predict, or work within a business environment that is in flux, broadbanding offers a program that is easier to maintain than a traditional system with many distinct levels.

One concern noted by companies that have implemented broadbanding is that compensation costs may go up. This is due to the wider than normal band taking away that more gradated top end control on salary levels. This can be effectively managed through the use of market data, in order to help managers to validate their pay decisions for a particular employee to the external market before proceeding to give higher than normal pay increases.

\section{Salary Structure Creation}

Salary structure creation is the most important step, chartered with indicating rates of pay for different jobs, providing scope for pay progression via performance, competence, contribution, skill or service and containing pay ranges for jobs grouped into grades, individual jobs or job families. In this step, the internal structure is merged with the external market pay rates in a simple regression to develop a market pay line. Depending on whether the private institution wants to lead, lag or meet the market, the market pay line can be adjusted up or down. To complete the pay structure, pay grades and pay ranges are developed.

\section{Salary Adjustment}

If the institutions want to keep the salaries down, selecting some salary control systems is very important, in which salary survey is a good method to find out what other institution are paying their employees. So here are two common types of salary adjustments. One is a general adjustment that applies to the entire salary structure (i.e., salary scale) and is applicable to all employees at and below the maximum of the salary range of their position and is not contingent on performance or service in a position. The second type of adjustment is known as step progression. Employees compensated at a step or below in the salary range of their position are normally eligible for a one step increase in salary once a year based on a combination of satisfactory performance and service in their position. Employees whose performance does not fully meet expectations may be denied a step increase.

\section{References}

[1] Balkin D B, Gomez-Mejia L R. Toward a contingency theory of compensation strategy. Strategic management journal, 1987, 8(2): 169182.

[2] Milkovich G T, Newman J M, Milkovich C. Compensation. Burr Ridge, 
Ill.: Irwin/McGraw-Hill, 1999.

[3] McCormick E J. Job analysis: Methods and applications. New York: Amacom, 1979.

[4] Massey C D, Vincent J, Massey D. A Job Analysis of Major College Female Strength and Conditioning Coaches. The Journal of Strength \& Conditioning Research, 2012.

[5] McCormick E J, Jeanneret P R, Mecham R C. A study of job characteristics and job dimensions as based on the Position Analysis Questionnaire (PAQ). Journal of Applied Psychology, 1972, 56(4): 347.

[6] Sidanius J, Crane M. Job evaluation and gender: The case of university faculty. Journal of Applied Social Psychology, 1989, 19(2): 174-197.

[7] Robinson E S, Mee C L. Salary survey. Nursing2012, 2004, 34(10): 3639.

[8] Kelso Jr A S, Crawford V P. Job matching, coalition formation, and gross substitutes. Econometrica: Journal of the Econometric Society, 1982: 1483-1504.

[9] Zhong Tingyong,An Ye.The Relationship between Ownership Concentration, Equity Restriction and Firm Performance. The 3th (2011) International Conference on Financial Risk and Corporate Finance Management July 7- 8,2012 Dalian, China. 